\title{
HUBUNGAN PERILAKU DENGAN KEJADIAN TUBERKULOSIS PARU DI KABUPATEN MUNA
}

\author{
La Rangki ${ }^{1^{*}}$,Arfiyan Sukmadi ${ }^{2}$ \\ ${ }^{1,2}$ Program Studi Keperawatan, Fakultas Kedokteran, Universitas Halu Oleo, \\ Kampus Hijau Bumi Tridharma Anduonohu, Kendari, Sulawesi Tenggara. \\ email: larangki@uho.ac.id
}

Diterima : Desember 2021, Diterbitkan : Desember 2021

\begin{abstract}
Abstrak
Riset Kesehatan Dasar tahun 2018 melaporkan bahwa Provinsi Sulawesi Tenggara mendekati angka nasional pada prevalensi TB Paru berdasarkan riwayat diagnosis dokter menurut provinsi, yakni $0,41 \%$ sedangkan angka nasional sebesar $0,42 \%$. Prevalensi TB Paru berdasarkan riwayat diagnosis dokter di Kabupaten Muna mencapai 0,51\%, angka ini di atas angka Provinsi Sulawesi Tenggara. Data suspek TB Paru di Puskesmas Napabalano periode Januari sampai Desember tahun 2016 sebanyak 2,63\% kasus, kemudian periode Januari sampai Desember tahun 2017 terdapat 2,18\% kasus suspek TB paru. Penelitian ini bertujuan untuk mengidentifikasi hubungan perilaku dengan kejadian penyakit TB paru di Kecamatan Napabalano Kabupaten Muna. Desain penelitian korelasional dengan pendekatan crossectional, populasi penelitian adalah seluruh pasien suspek TB Paru di Kecamatan Napabalano Kabupaten Muna pada bulan Januari sampai Desember 2017 berjumlah 261 kasus dan sampel diambil dengan teknik Simple Random Sampling. Perilaku berhubungan secara signifikan terhadap kejadian TB Paru di Kabupaten Muna dengan kekuatan hubungan 0,329. Diperlukan pemberian penyuluhan tentang perilaku pencegahan penyakit tuberkulosis.
\end{abstract}

Kata kunci: Kejadian TB Paru, Perilaku.

\begin{abstract}
The 2018 Basic Health Research reported that Southeast Sulawesi Province was close to the national figure on the prevalence of pulmonary TB based on a doctor's diagnosis history by province, which was $0.41 \%$ while the national figure was $0.42 \%$. The prevalence of pulmonary TB based on a doctor's diagnosis history in Muna Regency reaches $0.51 \%$, this figure is above the figure for Southeast Sulawesi Province. Data on suspected pulmonary TB at the Napabalano Health Center for the period January to December 2016 were 2.63\% of cases, then from January to December 2017 there were $2.18 \%$ suspected cases of pulmonary TB. This study aims to identify the relationship between behavior and the incidence of pulmonary TB disease in Napabalano District, Muna Regency. The research design was correlational with a cross-sectional approach, the study population was all suspected pulmonary TB patients in Napabalano District, Muna Regency from January to December 2017 totaling 261 cases and samples were taken using the Simple Random Sampling technique. Behavior is significantly related to the incidence of pulmonary TB in Muna District with the strength of the relationship 0.329. It is necessary to provide counseling about the behavior of preventing tuberculosis.
\end{abstract}

Keywords: Occurrence of Pulmonary TB, Behavior 


\section{PENDAHULUAN}

Tuberculosis (TB) adalah penyakit yang sangat menular dan insidennya tinggi di negara-negara berpenghasilan rendah yang disebabkan oleh Mycobacterium tuberculosis (M. tuberculosis). TB paru merupakan penyakit yang berkaitan erat dengan kepadatan penduduk, tingkat kemiskinan, dan rendahnya kebersihan. Penyakit ini dengan cepat meluas sehingga World Health Organization (WHO) pada tahun 1993 menyatakan keadaan darurat TB global (Mertaniasih, Koendhori, \& Kusumaningrum, 2019).

TB adalah salah satu dari 10 penyebab kematian dan penyebab utama dari agen infeksi tunggal (di atas HIV/AIDS) di dunia. Pada tahun 2017, TB menyebabkan sekitar 1,3 juta kematian (kisaran, 1,2-1,4 juta) di antara orang HIV-negatif dan ada tambahan 300.000 kematian akibat TB (kisaran, 266 000-335 000) di antara orang HIV-positif. Secara global, diperkirakan 10 juta orang (kisaran, 9,0-11,1 juta) menderita penyakit TB pada tahun 2017 sebanyak 5,8 juta pria dan 3,2 juta wanita serta 1,0 juta anak-anak. Kasus terjadi pada semua negara dan semua usia kelompok, tetapi $90 \%$ terjadi pada orang dewasa (berusia $>15$ tahun), 9\% adalah orang yang hidup dengan HIV ( $72 \%$ di Afrika) dan dua pertiganya di delapan negara: India $(27 \%)$, China (9\%), Indonesia (8\%), Filipina (6\%), Pakistan (5\%), Nigeria (4\%), Bangladesh (4\%) dan Afrika Selatan (3\%) (World Health Organization, 2018).

Penderita TB Paru tanpa sadar telah menyebarkan kuman melalui percikan dahak (droplet nuclei) ke udara bebas jika tidak membuang dahak secara benar. Pada saat penderita batuk dapat menghasilkan 3000 percikan dahak yang menguap ke udara bebas yang mampu bertahan dalam suhu kamar sekitar beberapa jam dan jika terhirup maka orang dapat terinfeksi. Namun percikan dahak dapat berkurang jika ventilasi atau aliran udara cukup dan terkena sinar matahari secara langsung.
Diperkirakan pada saat seorang penderita TB Paru BTA (+) batuk maka ia berpotensi menghasilkan ratusan bahkan ribuan bakteri yang bercampur dengan hembusan nafas penderita dan sangat memungkinkan untuk menularkan kepada 10-15 orang per tahun konsentrasi percikan dahak pada udara dan lamanya menghirup udara tersebut maka akan mempengaruhi seseorang terpajan kuman Mycobacterium Tuberculosis sehingga kemungkinan setiap kontak dengan orang lain akan tertular (Agustina \& Wahjuni, 2017).

Riset Kesehatan Dasar tahun 2018 melaporkan bahwa Provinsi Sulawesi Tenggara hampir mendekati angka nasional pada prevalensi TB Paru berdasarkan riwayat diagnosis dokter menurut provinsi, yakni $0,41 \%$ sedangkan angka nasional sebesar 0,42\% (Kementerian Kesehatan RI, 2019). Laporan Provinsi Sulawesi Tenggara Riset Kesehatan Dasar 2018 menyebutkan bahwa Kabupaten Muna mencapai $0,51 \%$ pada prevalensi TB Paru berdasarkan riwayat diagnosis dokter menurut kabupaten/kota, angka ini di atas angka Provinsi Sulawesi Tenggara (Hutama, Riyanti, \& Kusumawati, 2019).

Kabupaten Muna Provinsi Sulawesi Tenggara menempati posisi kelima terbanyak jumlah kasus baru BTA+ di Provinsi Sulawesi Tenggara setelah Kabupaten Buton, Bau-Bau, Konawe Utara dan Konawe. Kasus TB di wilayah Kabupaten Muna cukup tinggi, dimana data kasus baru BTA+ pada tahun 2016 sebanyak 4,69\% kasus, data rekam medik di Puskesmas Napabalano kejadian TB paru tahun 2016 periode Januari-Desember sebanyak 2,63\% suspek kasus, sedangkan pada tahun 2017 periode Januari Desember suspek kejadian TB paru sebanyak 2,18\% kasus (Marhamah, 2019).

Penelitian Marhamah menyebutkan bahwa dalam praktik mencegah penularan 
TB Paru pada penderita. Tuberkulosis paru di Balai Kesehatan Masyarakat Wilayah Magelang dengan kategori tinggi atau baik (66\%), lebih banyak dibandingkan dengan kategori rendah atau buruk (34\%) (Marhamah, 2019) Penelitian lain oleh Herdianti et al., mengemukakan bahwa dari 68 orang pasien Tuberkulosis Paru di Pusat Kesehatan Muara Kumpeh di Kabupaten Muaro Jambi pada tahun 2018, yang terbanyak 54 orang atau 79,4 \% perilaku pencegahan Tuberkulosis paru yang buruk (Herdianti, Entianopa, \& Sugiarto, 2020). Hendrik L. Blum (1974) dalam Notoatmodjo, menjelaskan empat faktor yang mempengaruhi status kesehatan manusia, yaitu: lingkungan, perilaku, pelayanan kesehatan dan keturunan. Diantara keempat faktor tersebut, faktor perilaku masyarakat memiliki pengaruh besar terhadap pencegahan penyakit menular termasuk TB paru. Perilaku tersebut menurut Benyamin Bloom (1908) mencakup tiga domain, yaitu pengetahuan (knowledge), sikap (attitude), dan tindakan atau praktik (practice) (Agustina \& Wahjuni, 2017). Hubungan erat dan saling mempengaruhi antara perilaku dan pengetahuan dibuktikan oleh Maria dalam penelitiannya tahun 2020, bahwa diperoleh nilai $r=0,009$ dengan nilai $\alpha=0,05$ pada hubungan antara pengetahuan keluarga dengan perilaku pencegahan penularan TB Paru (Herdianti et al., 2020).

Penelitian oleh Zulaikhah tahun 2019 mengemukakan bahwa lingkungan rumah, pengetahuan dan perilaku berhubungan dengan kejadian TB paru di wilayah kerja puskesmas Bandarharjo Semarang dan faktor yang paling dominan berhubungan adalah pengetahuan (Putra, Wiliyanarti, \& Annisa, 2020). Mengingat bahwa tuberkulosis paru dapat memiliki akibat fatal dan kematian, keluarga atau masyarakat harus mengetahui dan memahami berbagai masalah dan dampak penyakit, khususnya TBC paru. Perilaku memainkan peran penting dalam upaya pencegahan dan penularan penyakit TBC paru. Tujuan dari penelitian ini adalah untuk mengidentifikasi hubungan perilaku dengan kejadian TB Paru di Kabupaten Muna, Sulawesi Tenggara tahun 2018.

\section{METODE PENELITIAN}

Jenis penelitian ini adalah kuantitatif dengan pendekatan pengambilan data menggunakan crossectional, sedangkan rancangan penelitian yaitu studi korelasional. Penelitian ini telah dilaksanakan mulai tanggal 14 November sampai dengan 28 November 2018 di Kecamatan Napabalano Kabupaten Muna. Populasi seluruh pasien yaitu suspek TB paru yang berada di Kecamatan Napabalano Kabupaten Muna mulai Januari sampai Desember Tahun 2017 berjumlah 261 kasus. Sampel sebagian pasien yaitu suspek TB paru yang berada di Kecamatan Napabalano Kabupaten Muna mulai Januari sampai Desember tahun 2017 yang memenuhi kriteria inklusi. Teknik pengambilan sampel yang digunakan secara Simple Random Sampling. Analisis univariat dengan mendekripsikan karakteristik sampel terkait dengan variabel penelitian dalam bentuk persentase dan analisis bivariat untuk menguji hipotesis dengan menganalisis adanya hubungan antara variabel independen dan variabel dependen data kategorik menggunakan uji Kendall Tau.

\section{HASIL DAN PEMBAHASAN}

\section{A. Karakteristik Responden}

1. Usia responden

\begin{tabular}{crccccc}
\hline \multirow{2}{*}{ Usia } & \multicolumn{6}{c}{ Kejadian TB paru } \\
\cline { 2 - 7 } & \multicolumn{2}{c}{ TB } & \multicolumn{2}{c}{ Non TB } & \multicolumn{2}{c}{ Jumlah } \\
\cline { 2 - 7 } & $\mathbf{n}$ & $\mathbf{\%}$ & $\mathbf{n}$ & $\mathbf{\%}$ & $\mathbf{N}$ & $\mathbf{\%}$ \\
\hline $26-35$ & 2 & 3,5 & 2 & 3,5 & 4 & 3.5 \\
\hline $36-45$ & 29 & 50,9 & 28 & 49,1 & 57 & 50.0 \\
\hline $46-55$ & 20 & 35,1 & 21 & 36,8 & 41 & 36.0 \\
\hline $56-65$ & 6 & 10,5 & 6 & 10,5 & 12 & 10.5 \\
\hline Jumlah & $\mathbf{5 7}$ & $\mathbf{1 0 0}$ & $\mathbf{5 7}$ & $\mathbf{1 0 0}$ & $\mathbf{1 1 4}$ & $\mathbf{1 0 0}$ \\
\hline
\end{tabular}

Sumber: Data primer, 2018 
Jumlah dan persentase responden dari 114 responden di Kecamatan Napabalano Kabupaten Muna berdasarkan umur responden terbanyak pada kelompok umur 46-55 tahun berjumlah 41 responden $(36,0 \%)$ dan responden yang paling sedikit kelompok umur 26-35 tahun berjumlah 4 responden $(3,5 \%)$.

\section{Jenis Kelamin}

\begin{tabular}{|c|c|c|c|c|c|c|}
\hline \multirow{3}{*}{$\begin{array}{c}\text { Jenis } \\
\text { Kelamin }\end{array}$} & \multicolumn{6}{|c|}{ Kejadian TB paru } \\
\hline & \multicolumn{2}{|c|}{ TB } & \multicolumn{2}{|c|}{ Non TB } & \multicolumn{2}{|c|}{ Jumlah } \\
\hline & $\mathbf{n}$ & $\%$ & $\mathbf{n}$ & $\%$ & $\mathbf{N}$ & $\%$ \\
\hline Laki-Laki & 44 & 77,2 & 44 & 77,2 & 88 & 77.2 \\
\hline erem & 13 & 22,8 & 13 & 22,8 & 26 & 22.8 \\
\hline Jumlah & 57 & 100 & 57 & 100 & 114 & 100 \\
\hline
\end{tabular}

Sumber: Data primer, 2018

Jumlah dan persentase responden dari 114 responden di Kecamatan Napabalano Kabupaten Muna berdasarkan jenis kelamin responden terbanyak laki-laki berjumlah 88 responden $(77,2 \%)$ dan perempuan berjumlah 26 responden (22,8\%).

\section{Pendidikan}

\begin{tabular}{lcccccc}
\hline & \multicolumn{6}{c}{ Kejadian TB paru } \\
\cline { 2 - 7 } Pendidikan & \multicolumn{2}{c}{ TB } & \multicolumn{2}{c}{ Non TB } & \multicolumn{2}{c}{ Jumlah } \\
\cline { 2 - 7 } & $\mathbf{n}$ & \% & n & \% & N & \% \\
\hline SD & 17 & 29,8 & 25 & 43,9 & 42 & 36.8 \\
\hline SMP & 20 & 35,1 & 18 & 31,6 & 38 & 33.3 \\
\hline SMA & 11 & 19,3 & 3 & 5,3 & 14 & 12.3 \\
\hline PT & 9 & 15,8 & 11 & 19,3 & 20 & 17.5 \\
\hline Jumlah & 57 & 100 & 57 & 100 & 114 & 100 \\
\hline
\end{tabular}

Sumber: Data primer, 2018

Jumlah dan persentase responden dari 114 responden di Kecamatan Napabalano Kabupaten Muna berdasarkan tingkat pendidikan responden terbanyak SD berjumlah 42 responden (36,8\%). Sedangkan responden yang paling sedikit pendidikan SMA berjumlah 14 responden $(12,3 \%)$.

\section{Pekerjaan}

\begin{tabular}{lcccccc}
\hline \multirow{2}{*}{ Pekerjaan } & \multicolumn{6}{c}{ Kejadian TB paru } \\
\cline { 2 - 7 } & \multicolumn{2}{c}{ TB } & \multicolumn{3}{c}{ Non TB } & \multicolumn{2}{c}{ Jumlah } \\
\cline { 2 - 7 } & $\mathbf{n}$ & $\mathbf{\%}$ & $\mathbf{n}$ & $\mathbf{\%}$ & $\mathbf{N}$ & $\boldsymbol{\%}$ \\
\hline Wiraswasta & 48 & 84,2 & 44 & 77,2 & 92 & 80.7 \\
\hline PNS & 4 & 7,0 & 12 & 21,1 & 16 & 14.0 \\
\hline
\end{tabular}

\begin{tabular}{ccccccc}
\hline IRT & 5 & 8,8 & 1 & 1,8 & 6 & 5.3 \\
\hline Jumlah & 57 & 100 & 57 & 100 & 114 & 100 \\
\hline
\end{tabular}

Sumber: Data primer, 2018

Jumlah dan persentase responden dari 114 responden di Kecamatan Napabalano Kabupaten Muna berdasarkan pekerjaan responden terbanyak Wiraswasta berjumlah 92 responden (80,7\%). Sedangkan responden yang paling sedikit pekerjaannya ibu rumah tangga berjumlah 6 responden $(5,3 \%)$.

B. Analisis Bivariat

\begin{tabular}{|c|c|c|c|c|c|c|c|}
\hline \multirow{3}{*}{ Perilaku } & \multicolumn{6}{|c|}{ Kejadian TB paru } & \multirow{3}{*}{$\begin{array}{c}P \text { - } \\
\text { value }\end{array}$} \\
\hline & \multicolumn{2}{|c|}{ TB } & \multicolumn{2}{|c|}{ Non TB } & \multicolumn{2}{|c|}{ Jumlah } & \\
\hline & $\mathbf{n}$ & $\%$ & $\mathbf{n}$ & $\%$ & $\mathbf{N}$ & $\%$ & \\
\hline Kurang & 25 & 43,9 & 8 & 14,0 & 33 & 28,9 & \\
\hline Cukup & 32 & 56,1 & 49 & 86,0 & 81 & $\overline{71,1}$ & 0.000 \\
\hline Jumlah & 57 & 100 & 57 & 100 & 114 & 100 & \\
\hline
\end{tabular}

Sumber: Data primer, 2018

Berdasarkan perilaku dari 114 responden di Kecamatan Napabalano Kabupaten Muna terbanyak cukup berjumlah 81 responden $(71,1 \%)$ terdiri dari menderita TB Paru berjumlah 32 responden $(56,1 \%)$ dan tidak menderita TB Paru berjumlah 49 responden $(86,0 \%)$. Sedangkan responden yang kurang pengetahuannya berjumlah 33 responden (28,9\%) terdiri dari menderita TB Paru berjumlah 25 responden $(43,9 \%)$ dan tidak menderita TB Paru berjumlah 8 responden $(14,0 \%)$.

Penyakit TBC merupakan penyakit yang dapat dicegah dan disembuhkan. Perilaku pencegahan penularan TB penting untuk memutuskan mata rantai penularan, hal ini merupakan tujuan utama pengobatan TB selain mencegah kekambuhan dan mengobati pasien (Glaziou, Floyd, \& Raviglione, 2018).

Beberapa penelitian menunjukkan sedikit perawatan yang dilakukan untuk mencegah penularan penyakit ini. Penelitian di Thailand hanya $25,78 \%$ dan penelitian lain menyebutkan $43,6 \%$ yang menerapkan perilaku pencegahan penularan TB yang baik (Thwin \& Chapman, 2009). Perilaku pencegahan 
penularan adalah dengan penggunaan masker, tidak sembarangan meludah, minum obat secara teratur, dan mengatur kebersihan rumah tangga (ventilasi, penerangan sinar matahari, dan mengeringkan bantal kasur). Namun masih sedikit yang menerapkan etika batuk dengan menutup mulut dengan siku, tisu, atau sapu tangan. Sebagian besar menutup mulut mereka dengan tangan. Hal ini jika Anda tidak segera mencuci tangan, Anda akan mudah menulari orang lain atau benda yang disentuhnya.

Hasil uji korelasi berdasarkan perilaku terhadap kejadian TB Paru diperoleh nilai signifikansi $p=0,000$ dengan koefisien korelasi sebesar 0,329 artinya keeratan hubungan antar variabel dalam kategori cukup.

Berdasarkan frekwensi terbanyak variabel perilaku kategori cukup baik, tidak menderita TB Paru sebesar 86,0\% menunjukkan bahwa kategori perilaku yang cukup baik, responden cenderung tidak menderita TB Paru, adanya responden yang menderita TB Paru 56,1\% hal ini dapat disebabkan faktor lain selain status perilakunya seperti daya tahan tubuh penderita yang tidak baik, kurangnya informasi yang diperoleh dan pendidikan kesehatan yang masih kurang karena pelaksanaannya tidak rutin dilakukan oleh petugas kesehatan.

Responden dengan perilaku kurang baik, menderita TB Paru sebesar 43,9\% menunjukkan bahwa perilaku kurang cenderung menderita TB Paru, adanya tidak menderita TB Paru sebesar 14,0\% dapat disebabkan faktor lain selain perilaku seperti sudah baiknya daya tahan tubuh seseorang.

Sesuai teori bahwa promosi kesehatan sangat berperan dan berpengaruh terhadap perilaku seseorang karena dimana kegiatan promosi yang dilakukan dengan cara menyebarkan pesan, menanamkan keyakinan sehingga masyarakat tidak hanya sadar, tahu dan mengerti, tetapi juga bisa melaksanakan suatu anjuran yang ada hubungannya dengan kesehatan (Agustina \& Wahjuni, 2017).

Faktor lain seperti kesadaran seseorang dalam pencegahan penyakit TB paru yang kurang, walaupun pengetahuannya cukup tidak melakukan pencegahan maka dapat mengalami infeksi TB paru seperti masyarakat tidak segera melaporkan kepada petugas kesehatan setempat jika menemukan penderita tuberkulosis atau diduga menderita tuberkulosis, masyarakat setiap membuang dahak dan meludah sembarang tempat, jika responden batuk, tidak selalu menutup hidung atau mulut menggunakan tisu atau sapu tangan, masyarakat tidak segera membuang tisu tersebut ke tempat sampah atau membuang sembarang tempat.

Hasil penelitian menunjukkan nilai koefisien korelasi antara perilaku terhadap kejadian TB Paru di Kecamatan Napabalano Kabupaten Muna Tahun 2018 sebesar 0,329 yang berarti memiliki tingkat hubungan dalam kategori cukup.

Perilaku berhubungan cukup erat dengan kejadian TB Paru karena perilaku kesehatan yang kurang dalam pencegahan penyakit TB paru, sehingga seseorang mudah terpapar penyakit Tuberkulosis apabila tidak disertai kesadaran dalam berperilaku pencegahan seperti deteksi dini penyakit tuberkulosis (Herdianti et al., 2020)

Perilaku pencegahan transmisi tuberkulosis paru merupakan salah satu kunci untuk penurunan insiden penyakit tuberkulosis paru. Perilaku tidak sehat pada pasien dengan tuberkulosis paru dapat disebabkan karena kurangnya informasi tentang TB di masyarakat sehingga mereka kurang bertanggung jawab atas penularan tuberkulosis. Untuk menilai kebiasaan dalam mencegah transmisi tuberkulosis paru, diperlukan perubahan perilaku di masyarakat.

Berdasarkan hasil dan pembahasan dapat disimpulkan bahwa responden yang perilakunya kurang baik cenderung menderita tuberkulosis paru dan 
sebaliknya responden yang perilakunya cukup cenderung tidak menderita tuberkulosis paru, oleh karena itu disarankan perlu bagi responden meningkatkan perilaku dalam pencegahan penyakit tuberkulosis seperti meningkatkan kesadaran deteksi dini penyakit tuberkulosis paru, peranan masyarakat dalam deteksi dini tuberkulosis berguna untuk menghindari penularan, meningkatnya kasus, dengan demikian masyarakat akan selalu belajar dari pengalaman-pengalaman sebelumnya dalam arti seseorang lebih pandai jika belajar dari apa yang dialaminya sendiri dari pada harus melihat dari orang lain.

Perilaku pencegahan TB Paru dapat diwujudkan dalam bentuk tindakan keseharian penderita dalam pencegahannya. Hasil penelitian menunjukkan perilaku yang baik pada beberapa item dan juga terdapat beberapa item dengan perilaku yang kurang baik. Perilaku responden yang baik dalam 3 hal yaitu membuka pintu setiap pagi, mencuci tangan dengan sabun, dan mencuci tangan dengan air mengalir merupakan suatu kebiasaan masyarakat yang sudah melekat baik sebelum responden menderita TB Paru, sehingga saat responden menderita TB Paru, perilaku itu masih tetap dilakukan. Selain itu, hampir seluruh responden menyadari bahwa sirkulasi udara dalam ruangan/kamar responden juga sangat berpengaruh terhadap penularan TB Paru, maka hampir seluruh responden membuka jendela kamar setiap pagi dan telah memiliki ventilasi pada kamar (Hutama et al., 2019).

\section{SIMPULAN}

Perilaku secara signifikan berhubungan dengan kejadian TB Paru dengan nilai $p=0,000$ dan memiliki kekuatan hubungan sebesar 0,329 atau dalam kategori cukup.

\section{DAFTAR PUSTAKA}

Agustina, S., \& Wahjuni, C. U. (2017). Pengetahuan dan tindakan pencegahan penularan penyakit tuberkulosa paru pada keluarga kontak serumah. Jurnal Berkala Epidemiologi, 5(1), 85-94.

Glaziou, P., Floyd, K., \& Raviglione, M. C. (2018). Global epidemiology of tuberculosis. Paper presented at the Seminars in respiratory and critical care medicine.

Herdianti, H., Entianopa, E., \& Sugiarto, S. (2020). Effect of Patient's Personal Character on Prevention of Transmission of Pulmonary TB. Indonesian Journal of Tropical and Infectious Disease, 8(1), 9-15.

Hutama, H. I., Riyanti, E., \& Kusumawati, A. (2019). Gambaran perilaku penderita TB paru dalam pencegahan penularan TB paru di Kabupaten Klaten. Jurnal Kesehatan Masyarakat (Undip), 7(1), 491-500.

Kementerian Kesehatan RI. (2019). Laporan Nasional RISKESDAS 2018. Jakarta: Lembaga Penerbit Badan Penelitian dan Pengembangan Kesehatan.

Marhamah, E. (2019). Beberapa faktor yang mempengaruhi praktik pencegahan penularan TB paru pada penderita TB paru positif di Balai Kesehatan Masyarakat Wilayah Magelang. Berita Kedokteran Masyarakat, 35(4), 1-1.

Mertaniasih, N. M., Koendhori, E. B., \& Kusumaningrum, D. (2019). Buku Ajar Tuberkulosis Diagnostik Mikrobiologis: Airlangga University Press.

Putra, K. W. R., Wiliyanarti, P. F., \& Annisa, F. (2020). ANALYSIS OF PREVENTION BEHAVIORS OF PULMONARY TUBERCULOSIS TRANSMISSION QUESTIONNAIRE (PBPTTQ). 
Nurse and Health: Jurnal Keperawatan., 9(1), 16-22.

Thwin, H. T., \& Chapman, R. S. (2009). Preventive Behaviors of Tuberculosis among Myanmar Migrants at Muang Disctrict, Phuket Province, Thailand. Journal of Health Research, 23(Suppl.), 65-67.
World Health Organization. (2018). Global tuberculosis report 2018. Geneva: World Health Organization; 2018. Licence: CC BY-NC-SA 3.0 IGO: WHO/CDS/TB/2018.20. Available from: http://apps. who. int/iris/bitstream .... 